\title{
Shaking table tests of structures with hysteretic dampers: experimental results versus prediction using non-linear static methods
}

\author{
Amadeo Benavent-Climent • David Escolano-Margarit
}

\begin{abstract}
The use of seismic hysteretic dampers for passive control is increasing exponentially in recent years for both new and existing buildings. In order to utilize hysteretic dampers within a structural system, it is of paramount importance to have simplified design procedures based upon knowledge gained from theoretical studies and validated with experimental results. Non-linear Static Procedures (NSPs) are presented as an alternative to the force-based methods more common nowadays. The application of NSPs to conventional structures has been well established; yet there is a lack of experimental information on how NSPs apply to systems with hysteretic dampers. In this research, several shaking table tests were conducted on two single bay and single story 1:2 scale structures with and without hysteretic dampers. The maximum response of the structure with dampers in terms of lateral displacement and base shear obtained from the tests was compared with the prediction provided by three well-known NSPs: (1) the improved version of the Capacity Spectrum Method (CSM) from FEMA 440; (2) the improved version of the Displacement Coefficient Method (DCM) from FEMA 440; and (3) the N2 Method implemented in Eurocode 8. In general, the improved version of the DCM and N2 methods are found to provide acceptable accuracy in prediction, but the CSM tends to underestimate the response.
\end{abstract}

Keywords Pushover analysis - Hysteretic damper - N2 method - Capacity spectrum method D Displacement coefficient method

\section{Introduction}

Hysteretic dampers are giving rise to technology capable of minimizing interstory drift and increasing the earthquake resistance of buildings. Hysteretic dampers have been used for a decade, and continue to attract attention in the field of earthquake engineering. In order to utilize hysteretic dampers within a structural system, it is necessary to have simplified 
design procedures based upon knowledge gained from theoretical studies and validated with experimental results. Conducting shaking table tests is the most realistic way to investigate experimentally the response of structural systems under dynamic seismic loading, and stands as a reliable approach to validate design procedures.

In recent decades the research community has recognized a need for change in seismic design methodology, towards new Performance Based Design (PBD) procedures that can account for the non-linear behaviour of structures during earthquakes in a simple manner. Clearly, non-linear time history analyses are the most reliable tool for estimating the inelastic response to a given accelerogram. But difficulties in correctly modelling the characteristics of cyclic load deformation of structural members, and the need of a set of ground motions that would properly define the seismic input at a given site, among other hindrances, make this method impractical for general use. The force-based methods currently implemented in seismic codes take into account the non-linear behaviour of structures during ground motions, using a behaviour factor to reduce the lateral forces of a modal response spectrum analysis. This approach focuses on determining the strength of the structure, providing a very rough estimation of the non-linear structural behaviour (Bosco et al. 2009). Consequently, there is a lack of a displacement-based methodology able to estimate the inelastic behaviour of structures without great computational efforts. Non-linear Static Procedures (NSP) have thus become a common tool under present standards Eurocode 8 (European Committee for Standarization 2002) and guidelines like FEMA-440 (Federal Emergency Management Agency 2005) to this end.

The most important NSP are: (1) the Capacity Spectrum Method (CSM) proposed by Freeman (1988) included in ATC-40 (Applied Technology Council 1996) and improved in FEMA-440; (2) the Displacement Coefficient Method (DCM) firstly presented in FEMA273, FEMA-274 (Federal Emergency Management Agency 1997) and FEMA-356 (Federal Emergency Management Agency 2000) and recently improved in FEMA-440; and (3) the N2 method developed by Fajfar (2000), Fajfar and Gaspersic (1996) and adopted by Eurocode 8 .

The main goal of all NSPs is to characterize the structural response induced by a design earthquake in terms of maximum displacement. All these methods are based on a process that involves two basic steps. The first step lies in determining an equivalent single-degreeof-freedom (SDOF) system, by means of the capacity curve obtained in a static push over (SPO) non-linear analysis. The second step is the characterisation of the seismic demand in terms of an over-damped elastic response spectrum (in the case of the CSM) or in terms of an inelastic design spectrum (in the case of the DCM and N2 methods). The maximum displacement is determined by the so-called 'performance point' or 'target displacement', as an indicator of the level of damage imparted to the structure. Although such methods fill the gap between current force-based methods and non-linear time history analysis, the background of all these procedures presents some limitations well reported in the literature (Krawinkler and Seneviratna 1998; Fragiacomo et al. 2006; Simon and D'Amore 1999).

Past research has studied the application of previous versions of the CSM from ATC-40 and DCM from FEMA-356 and the N2 method in conventional structures (Cardone 2007; Causevic and Mitrovic 2010; Lin et al. 2004). However, there is a lack of experimental evidence of how NSPs apply to structures with hysteretic dampers. In this paper, the seismic response of a structure equipped with hysteretic dampers predicted with the latest versions of the CSM and DCM methods and the N2 method is compared with the experimental results obtained in shaking table tests. 


\section{Test models and experimental results}

A prototype one-bay and one-story structure with $2.8 \mathrm{~m}$ height and $4.8 \times 4.8 \mathrm{~m}^{2}$ plan and a $0.25 \mathrm{~m}$ deep reinforced concrete (RC) slab supported by four box-type steel columns was designed according to Spanish codes for a Peak Ground Acceleration (PGA) of $0.34 \mathrm{~g}$ (here $\mathrm{g}$ is the acceleration of gravity).

\subsection{Description of the test models}

From the prototype structure, a reduced-scale test model satisfying the similitude laws was designed. The test model was derived applying the following scaling factors for geometry, acceleration and stress, respectively: $\lambda_{l}=1 / 2, \lambda_{a}=1$ and $\lambda_{\sigma}=1$. To ensure the consistency with the scaling factors used for the model, the accelerograms were scaled down in time by the factor $\lambda_{t}=\sqrt{\lambda_{l}}=\sqrt{1 / 2}$. Two identical test models were built in the Structural Engineering Laboratory at the University of Granada. In one of the models-referred to as FSD hereafter-two hysteretic dampers were installed. The other model-referred to as FS hereafter-did not have dampers. Figure $1 \mathrm{a}, \mathrm{b}$ show the geometry and reinforcing details of the test model FSD. The slab is $125 \mathrm{~mm}$ deep and it is reinforced with two steel meshes; one on the top with $6 \mathrm{~mm}$ diameter bars at $100 \mathrm{~mm}$, and another on the bottom consisting of $6 \mathrm{~mm}$ diameter bars at $75 \mathrm{~mm}$. The slab was reinforced at the corners by shear-heads consisting of $60 \mathrm{~mm}$ deep steel C-shapes, in order to prevent punching shear failure. The shape of the slab was a parallelepiped in which each pair of adjacent sides was perpendicular. The dimensions of the plate were $2,700 \times 2,700 \times 125 \mathrm{~mm}^{3}$. In plan, the plate (including the steel meshes used as bending reinforcement and the deep $\mathrm{C}$-shapes used as punching shear reinforcement at the corners) formed a $2,700 \times 2,700 \mathrm{~mm}^{2}$ parallelogram with two lines of symmetry parallel to each side and passing through its centroid. Figure 2 shows a detail of the slab. The average yield stress, $f_{s}$, of the reinforcing steel was $467 \mathrm{MPa}$, and the average concrete strength, $f_{c}=23.5 \mathrm{MPa}$. The columns were built with an $80 \times 80 \times 4 \mathrm{~mm}$ hollow-steel section. The average yield stress $f_{y}$ of the columns steel was $216 \mathrm{MPa}$ and the maximum stress $329 \mathrm{MPa}$. The hysteretic damper used in the tests has the form of a conventional brace and it is installed in the main structure as a standard diagonal bar. Each hysteretic damper is constructed by assembling five short length segments of I-shaped steel sections which constitute the energy dissipating device, and two U-shaped steel bars that function as auxiliary elements. The seismic damper dissipates the energy through plastic strains on the web of the I-shaped sections under out-of-plane flexure. The auxiliary elements are designed to remain elastic. A detailed description of the hysteretic damper can be found in Benavent-Climent et al. (2011). Figure 3 shows the hysteretic dampers installed in specimen FSD, which were connected to the main structure as shown in Fig. 1a. The procedure considered to design the hysteretic dampers is an energy-based method that is rooted in establishing the energy balance of the structure. Energy-based design procedures are particularly appropriate for designing structures incorporating passive damping mechanisms (Soong and Dargush 1997) and have recently been included in the Japanese seismic code (BSL 2009). The structure tested in this study can be idealized as a SDOF system. A detailed development of the equations required to design the dampers in this case can be found in the "Appendix". Using these equations, the hysteretic dampers were designed as follows. First, the lateral stiffness of the main structure ${ }_{f} k$ (i.e. without dampers), the mass $M$ and the corresponding period ${ }_{f} T$ were estimated as ${ }_{f} k=37.2 \mathrm{kN} / \mathrm{cm}, M=0.0739 \mathrm{kNs} 2 / \mathrm{cm}$ and ${ }_{f} T=0.28 \mathrm{~s}$. Second, a stiffness ratio $K={ }_{s} k /{ }_{f} k=2$ was discretionally adopted so that the damper yields far before the main structure reaches its elastic deformation capacity. Here ${ }_{s} k$ is the lateral stiffness provided by 

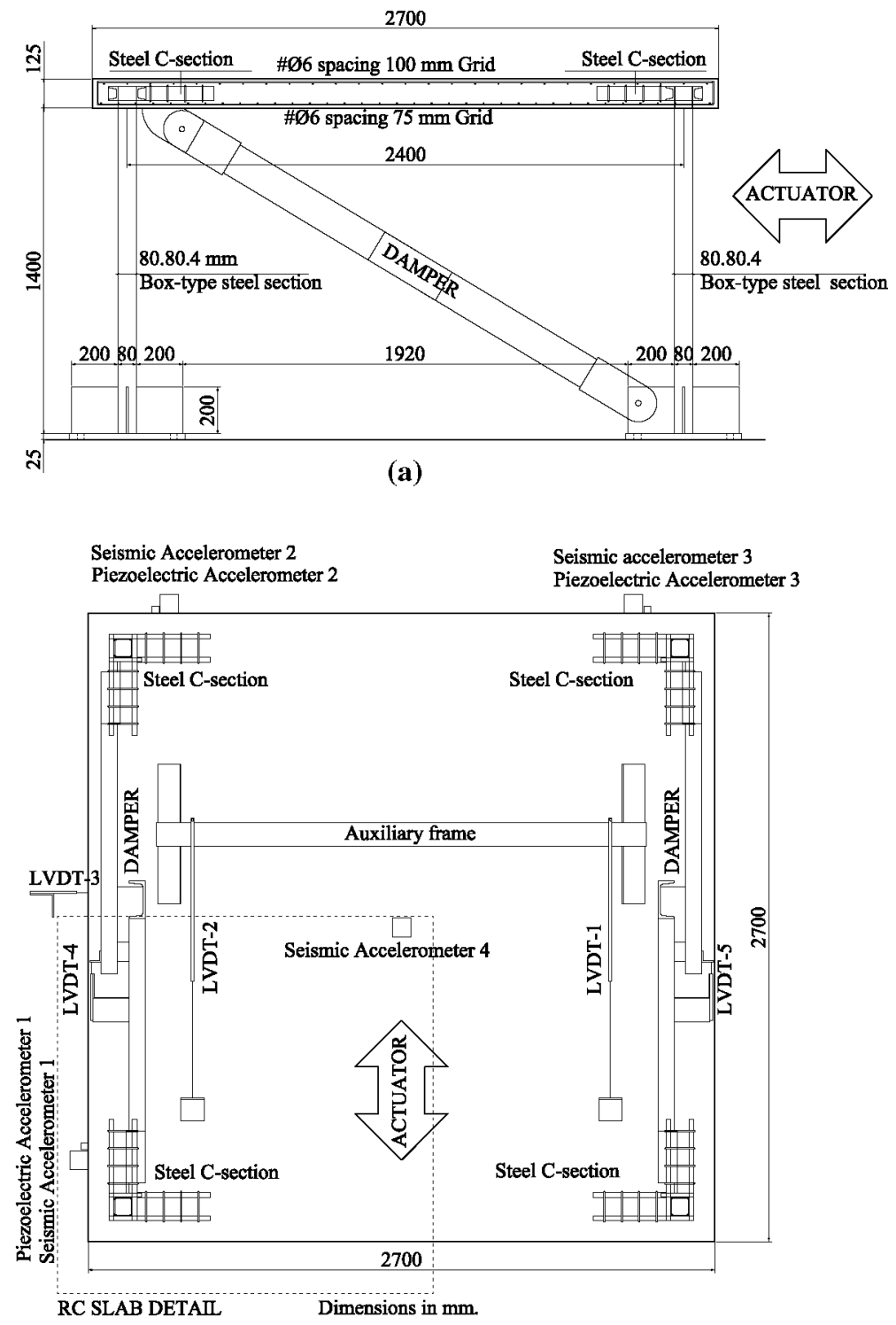

(b)

Fig. 1 Test model geometry and set-up. a Elevation, b plan (bottom view)

the dampers; ${ }_{s} k$ and lateral strength of the dampers. ${ }_{s} Q_{y}$ were determined using Eqs. (A.12) and (A.16) (see "Appendix"), so that the maximum lateral displacement of the structure $v_{\max }$ for a design earthquake of far-field type characterized by $I_{d}=18.5, T_{N H}=0.9 \mathrm{~s}$ and $V_{D}=70 \mathrm{~cm} / \mathrm{s}$ was $v_{\max }=12 \mathrm{~mm}$. The value adopted for $v_{\max }$ corresponds to a drift of $1 \%$ of story height. $I_{d}$ is a seismological parameter proposed by Cosenza and Manfredi (1997), $T_{N H}$ is the initial period of medium period region in the Newmark and Hall representation of the design earthquake, and $V_{D}$ is the energy input that contributes to damage expressed 


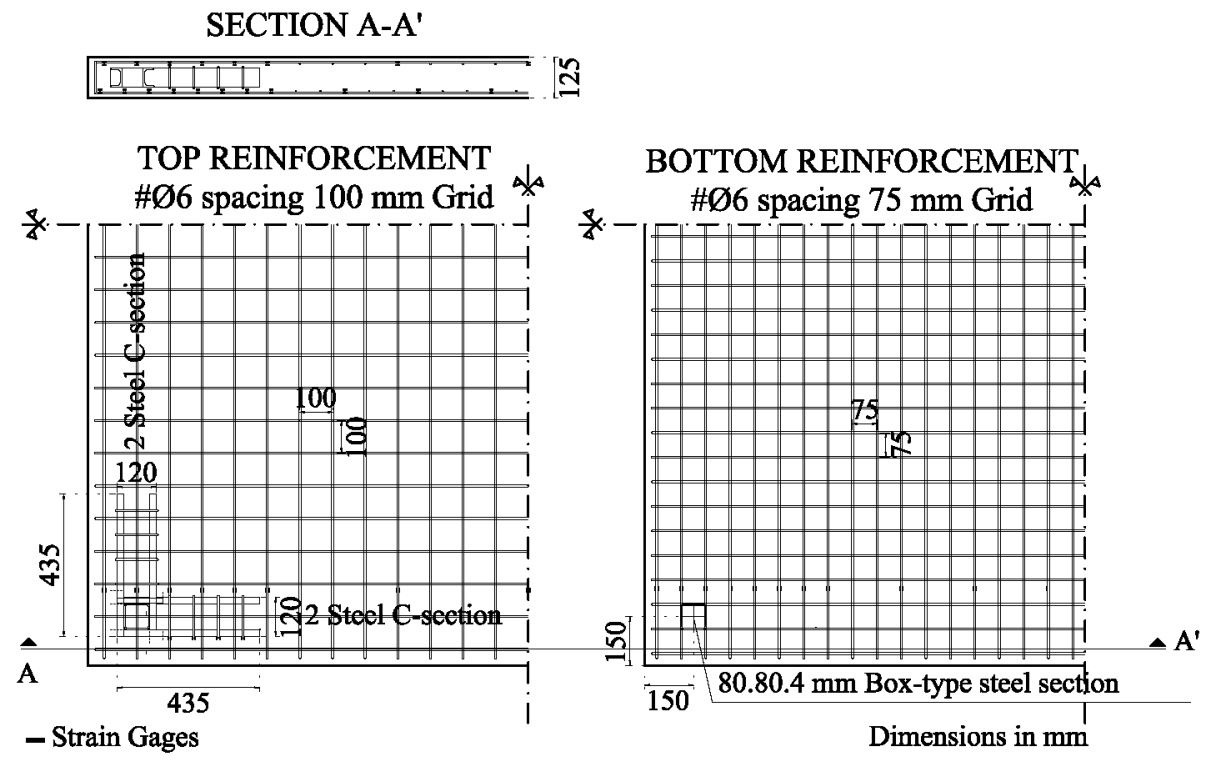

Fig. 2 Detail of the RC slab

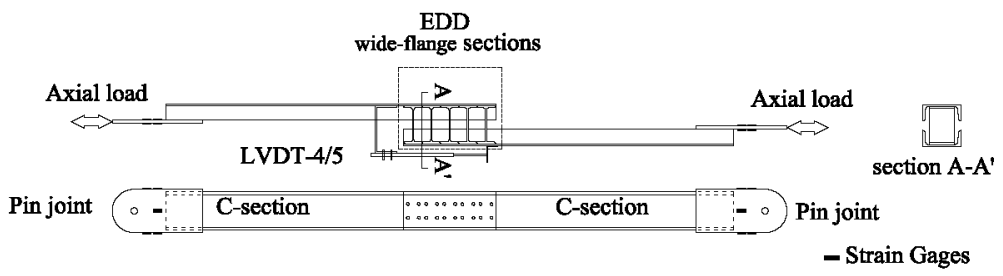

Fig. 3 Hystertic damper installed in FSD specimen

in terms of equivalent velocity. A more detailed explanation of these parameters is provided in the "Appendix". The values adopted for $I_{d}$ and $T_{N H}$ correspond to the Calitri $1980 \mathrm{NS}$ earthquake, and the value adopted for $V_{D}$ is representative of the seismic hazard in Granada, Spain (Benavent-Climent et al. 2002). $I_{d}, T_{N H}$ and $V_{D}$ were scaled by the corresponding factors to ensure consistency.

\subsection{Experimental set-up, instrumentation and load history}

The dynamic tests were carried out on the uniaxial MTS $3 \times 3$ m shaking table of the University of Granada. The test models were bolted to the shaking table as seen in Figs. 4 and 5. In order to satisfy the similitude laws between prototype and test model, additional mass was added to the top of the RC slab; the total mass including the steel blocks was $M=7.39 \mathrm{Ns}^{2} / \mathrm{mm}$. The MTS shaking table has a digital controller which provides for closed loop control of the system using three high-level control techniques: TVC (Three Variable Control) for high fidelity reproduction across a wide band width; DPS (Delta Pressure Stabilization) for effectively damping oil column compliance to allow for higher gain settings across a wider bandwidth; and SFL (Servovalve Flow Linearization) for effectively removing the inherent non-linearities present in the servohydraulic system. To track the acceleration performance 


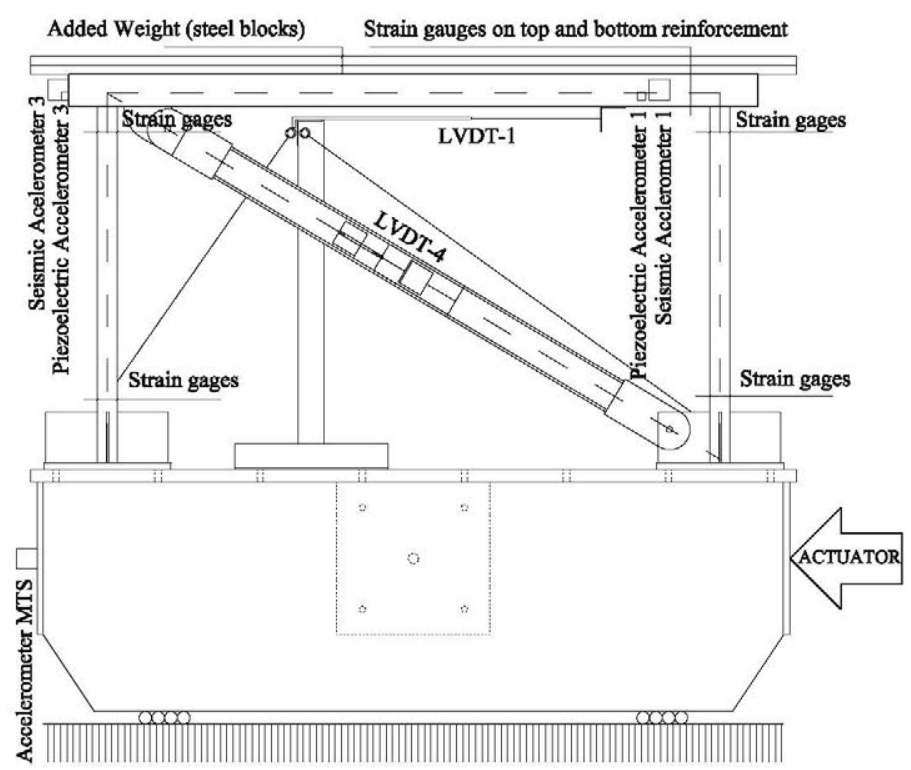

Fig. 4 Experimental set-up

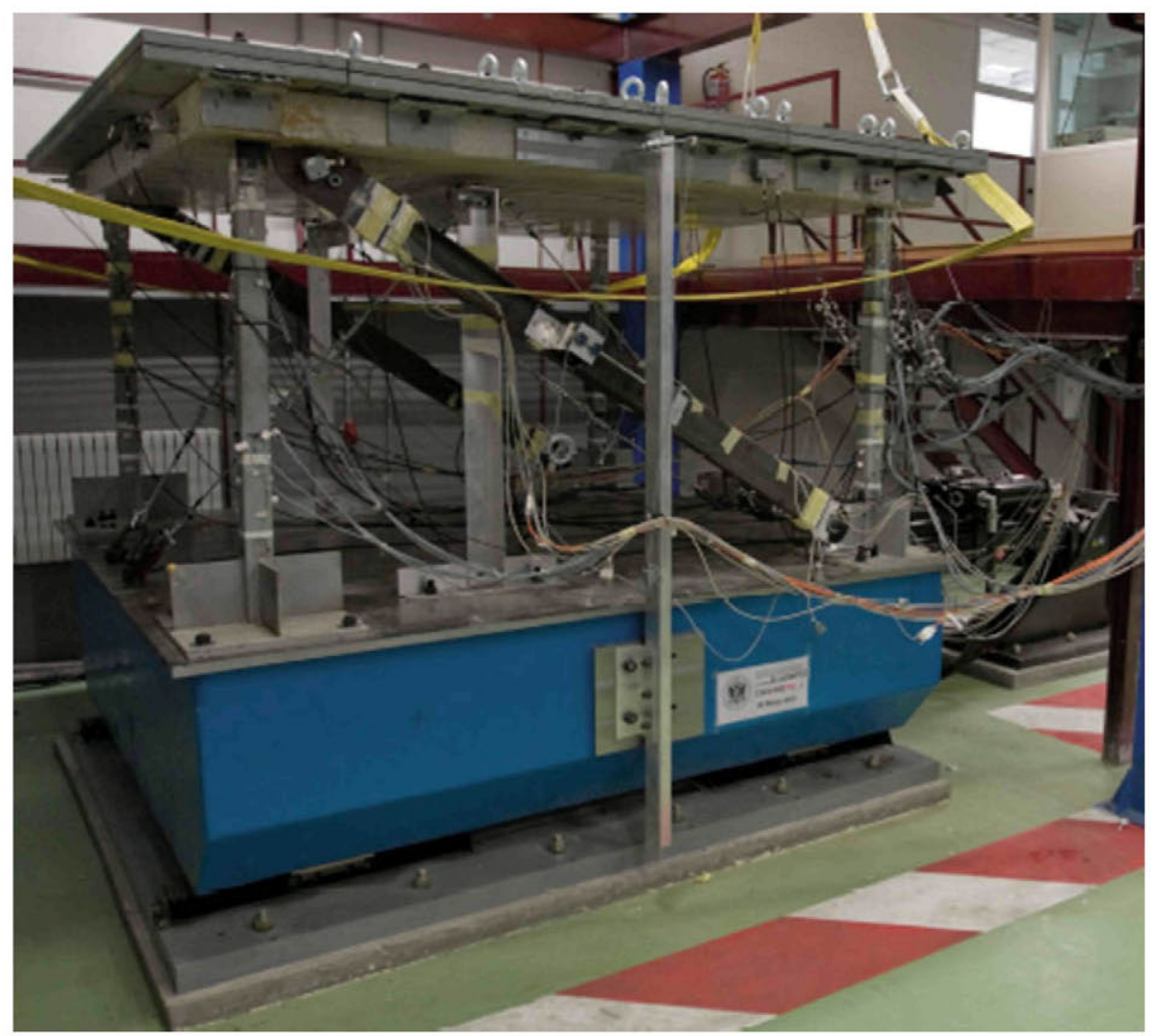

Fig. 5 Set-up overview 
of the table and improve the table response, the MTS shaking table includes two adaptative control techniques: the AIC (Adaptive Inverse Control) and the OLI (On-line Iteration). $\mathrm{AIC}$ is a control compensation technique that augments a fixed-gain controller to correct for closed loop gain and phase irregularities in order to improve control fidelity. It measures control system dynamics directly and modifies the control compensation accordingly in real time, making it possible to adapt to changing system dynamics. OLI is a control technique that repeatedly modifies the command input to a control system on an individual sampleby-sample basis until the control system response is an almost perfect replica of the desired command. OLI requires knowledge of transfer function of the equipment in order to compute a drive correction. The calibration of the system was conducted by moving the shaking table with the specimen mounted on it under acceleration control, as follows. First, a flat-shape random signal of root mean square (RMS) amplitude of about $0.05 \mathrm{~g}$ was applied to the table, and several parameters that govern the TVC system (dynamic force gain, displacement lead, velocity lead, acceleration jerk lead, acceleration gain, etc.) were adjusted so that the coherence of the transfer function (ratio between the reference acceleration and the feedback acceleration) was close to one in the bandwidth of $0-50 \mathrm{~Hz}$. Second, the AIC controller was trained in two consecutive phases. In the first phase, the forward transfer function was trained by moving the shaking table with a random signal with an RMS amplitude of about $0.05 \mathrm{~g}$. The second phase consisted of training the inverse transfer function. Third, the controller OLI was trained through an iterative process in which the shaking table was subjected to the desired accelerogram scaled to a low intensity of $0.1 \mathrm{~g}$. The gain was progressively reduced in each iteration until the errors between the desired acceleration and the actual acceleration measured on the table were reduced to acceptable values.

The models were tested applying to the shake table the Calitri 1980 NS earthquake signal (Campano-Lucano, Italy). Figure $6 \mathrm{a}, \mathrm{b}$ show the time history of ground acceleration $\ddot{v}_{g}$ and the $5 \%$ damped elastic response spectra in terms of absolute response acceleration $S_{a}$ normalized by PGA, corresponding to the original (unscaled) earthquake. Figure $6 \mathrm{c}$ shows the corresponding elastic response spectra for the earthquake signal scaled in time by the scaling factor $\lambda_{t}=\sqrt{1 / 2}$. Each specimen was subjected to a series of consecutive seismic simulations. In each seismic simulation the acceleration of the original record measured at Calitri during the Campano-Lucano earthquake was scaled by multiplying it by the factors of $1,2,3,4,5,6,7$ and 14 . The PGA of the earthquake signals obtained in this way were $0.16,0.31,0.47,0.62,0.78,0.94,1.10$ and $2.23 \mathrm{~g}$, respectively. Model FS was subjected to seven seismic simulations with the following PGA: $0.16,0.31,0.47,0.62,0.78,0.94$, and $1.10 \mathrm{~g}$. In turn, model FSD was subjected to eight shaking simulations with PGA equal to $0.16,0.31,0.47,0.62,0.78,0.94,1.10$, and $2.23 \mathrm{~g}$.

During each seismic simulation, displacements, strains and accelerations were acquired simultaneously. Data was continuously collected by a HBM MGC Plus data acquisition system using a sampling rate of $200 \mathrm{~Hz}$. Both FS and FSD models were instrumented with the following sensors:

(a) Two HBM inductive displacement transducers model WA-500, indicated as LVDT-1 and LVDT-2 in Fig. 1b. These sensors measured the relative horizontal displacement, $v$, between the shake table and the slab in the direction of the seismic loading;

(b) One HBM inductive displacement transducer model WA-100, indicated as LVDT-3 in Fig. 1b, that measured the relative displacement between the shake table and the slab in the direction perpendicular to the seismic loading.

(c) Three pairs of Bruel \& Kjaer piezoelectric and seismic accelerometers. The piezoelectric accelerometer was a miniature deltatron type 4507 . The seismic accelerometer was 


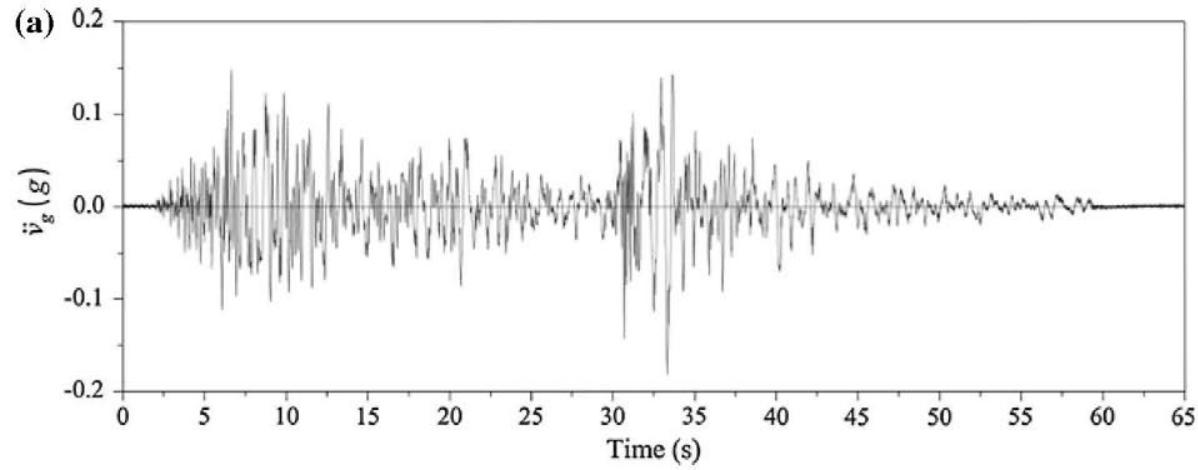

(b)

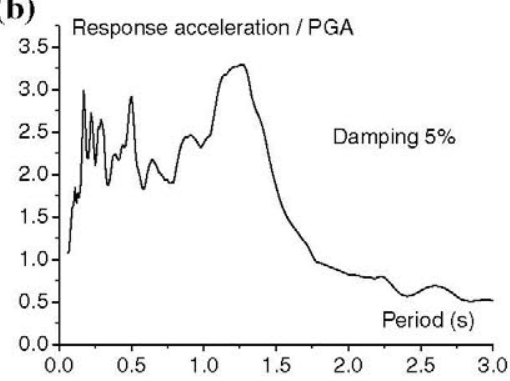

(c)

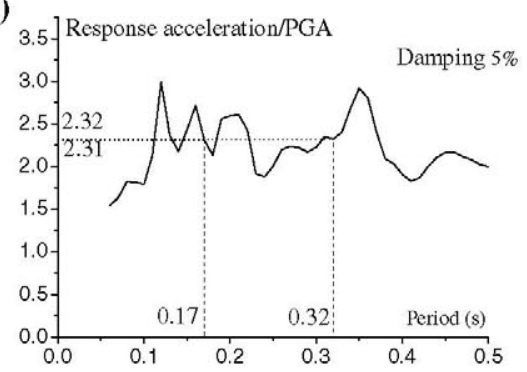

Fig. 6 Acceleration record used in the seismic simulations: a unscaled history of acceleration; $\mathbf{b}$ unscaled elastic response spectrum; $\mathbf{c}$ scaled elastic response spectrum

a deltatron type 8340 . They were fixed to the slab to measure its absolute response acceleration, $\ddot{v}^{t}$ as indicated in Fig. 1b. The pair formed by the piezoelectric accelerometer 2 and the seismic accelerometer 2 , and the pair formed by piezoelectric accelerometer 3 and seismic accelerometer 3 , measured accelerations in the direction of the seismic loading. The pair formed by the piezoelectric accelerometer 1 and the seismic accelerometer 1 measured the acceleration in the direction perpendicular to the seismic loading.

(d) An accelerometer labelled "Accelerometer MTS" in Fig. 4 was fixed to the shake table to measure the absolute table acceleration $\ddot{v}_{g}$ in the direction of the seismic loading.

e) Seventy-eight Tokyo Sokki Kenkyujo $120 \Omega$ electrical resistance strain gauges were attached to top and bottom longitudinal reinforcing bars prior to casting the concrete as shown in Fig. 2, and to the upper and lower ends of the columns as shown in Fig. 4.

Each damper installed in specimen FSD was instrumented with the following sensors:

(a) One HBM inductive displacement transducer model WA-100 indicated as LVDT-4 and LVDT-5 in Fig. 1b. Each sensor measured the axial deformation in one diagonal brace.

(b) Four Tokyo Sokki Kenkyujo $120 \Omega$ electrical resistance strain gauges were attached to both ends of the diagonal braces as shown in Fig. 3.

\subsection{Overall test results}

Figure 7 shows the time histories of the relative displacement $v$ of the slab with respect to the shaking table, in the direction of the shaking, for several seismic simulations. It was obtained by averaging the measurement provided by the displacements transducers LVDT-1 


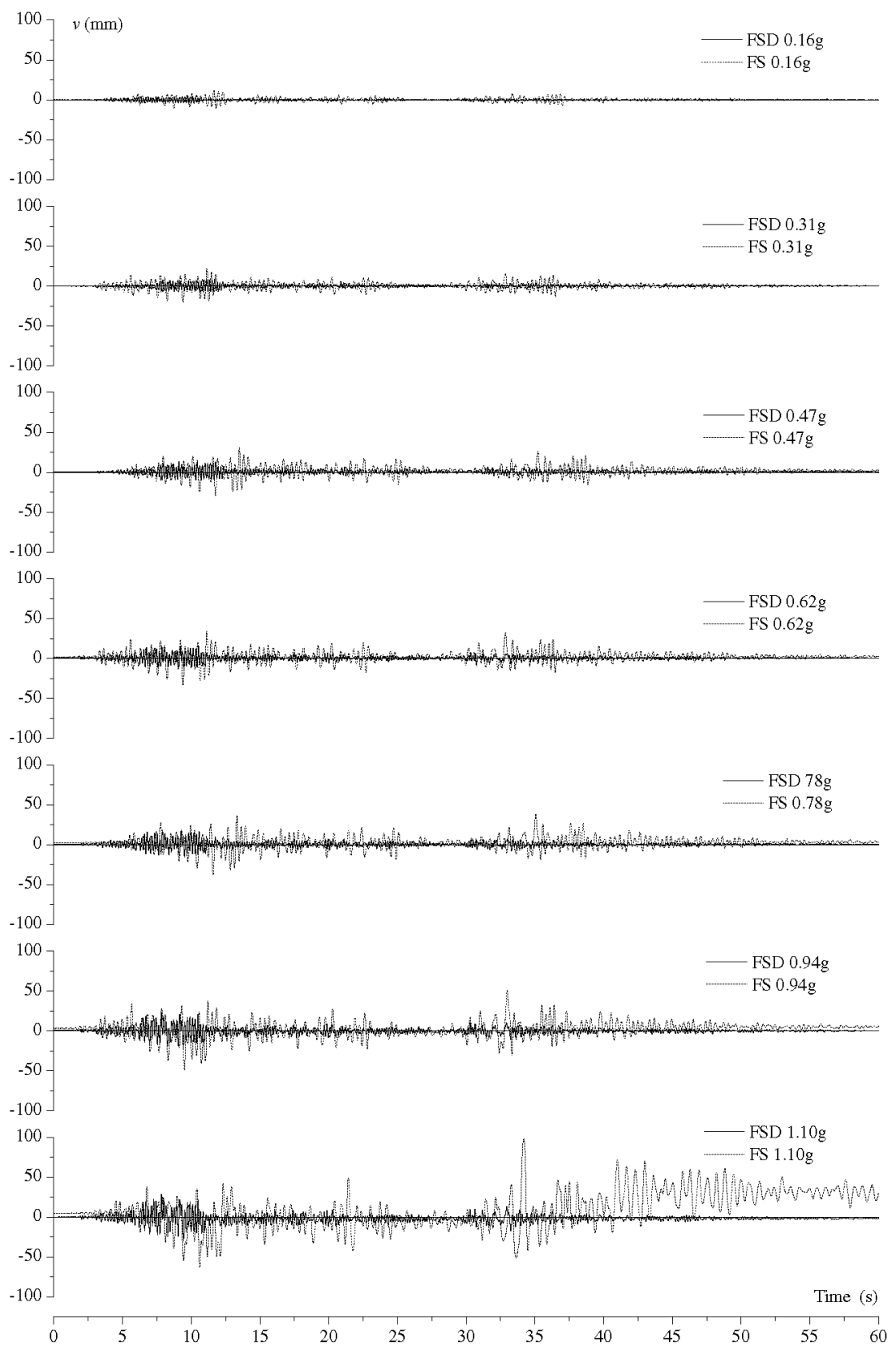

Fig. 7 Time histories of relative displacements of the slab for specimens FD and FSD

and LVDT-2 (see Figs. 1b, 4). Figure 8 shows the corresponding time histories of absolute response acceleration $\ddot{v}^{t}$ of the slab in the direction of the shaking. It is clear in the figures that the presence of hysteretic dampers significantly reduces the relative displacement of the structure while increasing the absolute response acceleration. Figure 9 shows the overall response 


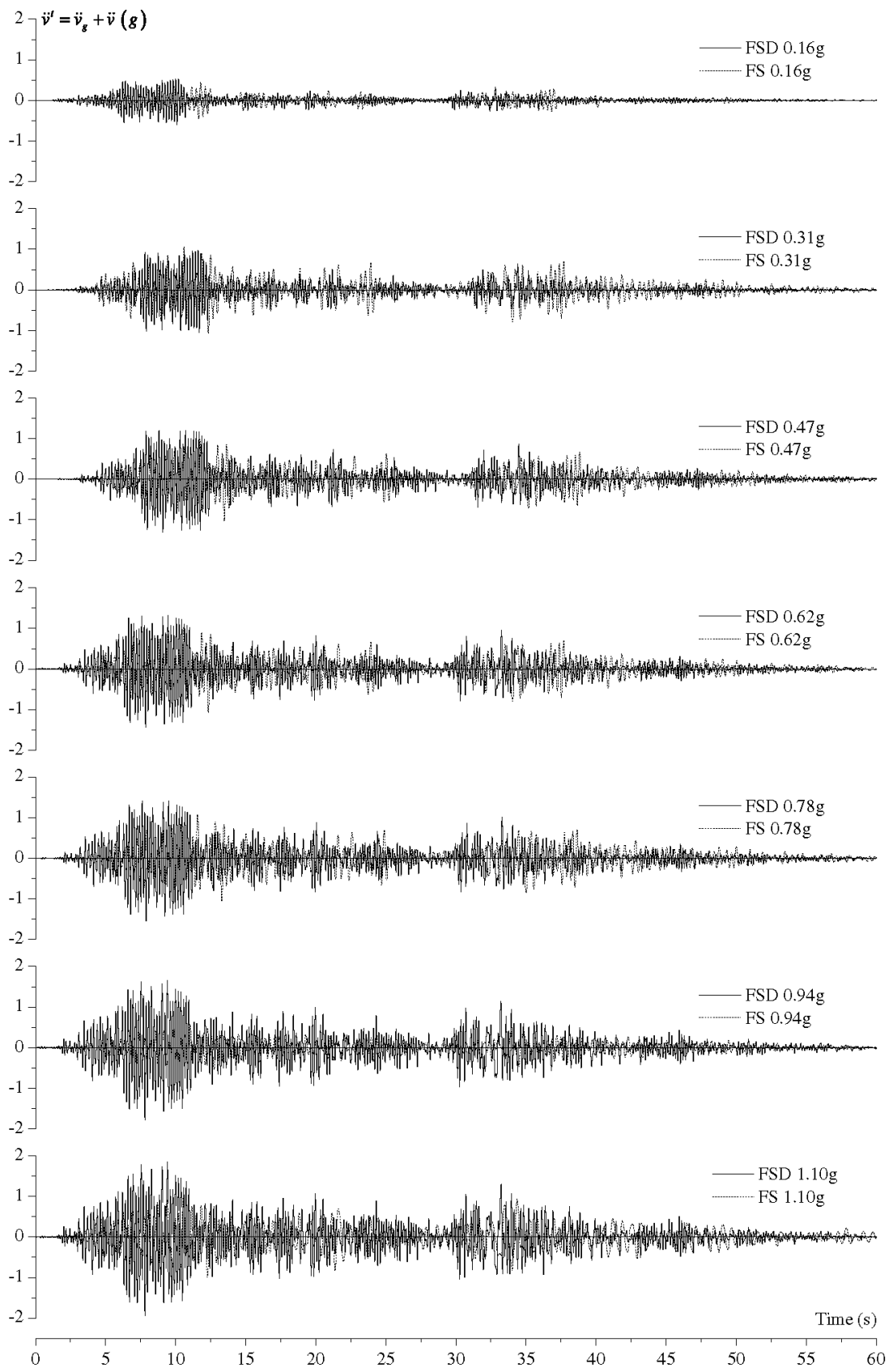

Fig. 8 Time histories of absolute response accelerations of the slab for specimens FD and FSD

of models FS and FSD during the seismic simulations with PGA equal to 0.16, 0.31, 0.47, $0.62,0.78,0.94$ and $1.1 \mathrm{~g}$. In the figures, the abscissa shows the relative displacement $v$ of the slab with respect to the shaking table. The ordinate shows the absolute response acceleration 
Fig. 9 Inertial force $m \ddot{v}^{t}$ versus lateral displacement $v$ obtained from tests for specimens FS and FSD
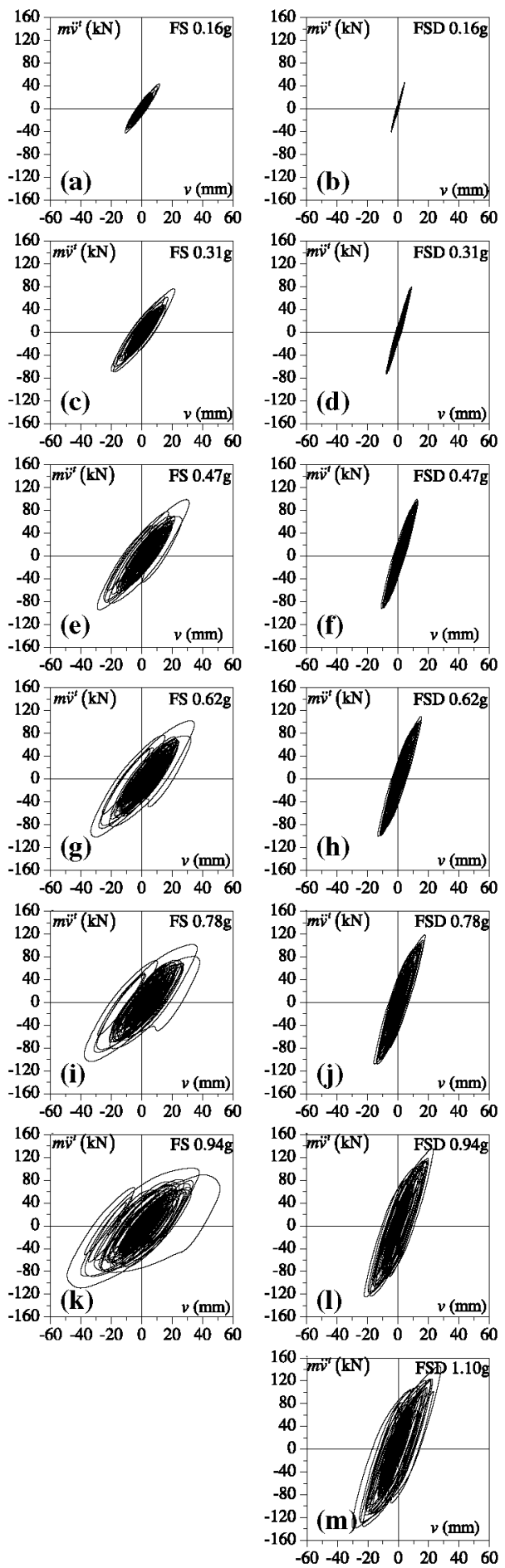
of the slab $\ddot{v}^{t}\left(=\ddot{v}+\ddot{v}_{g}\right)$ multiplied by the mass of the system (inertial force). In the seismic simulations with $\mathrm{PGA}=0.94 \mathrm{~g}$ the hysteretic dampers reduced the lateral displacement to approximately one half. In the seismic simulations with PGA0.78g the hysteretic dampers increased the maximum inertial force up to about $45 \%$; this increase reached $57 \%$ in the seismic simulation with $\mathrm{PGA}=0.94 \mathrm{~g}$ and $97 \%$ in the seismic simulation with $\mathrm{PGA}=1.1 \mathrm{~g}$. The maximum lateral force that can be sustained by each specimen is limited by its lateral strength. Since the lateral strength of the specimen with hysteretic dampers FSD is larger than that of the specimen without dampers FS, the maximum force of the former may increase with respect to the latter while the PGA input to the shaking table is the same. The specimen FS reached its limit lateral strength and yielded for $\mathrm{PGA}=0.47 \mathrm{~g}$, and consequently the maximum absolute response acceleration (and hence the maximum lateral force) remained almost constant in the seismic simulations with PGA $>0.47 \mathrm{~g}$. In contrast, in specimen FSD the plastification of the steel columns started during the seismic simulation corresponding to PGA $=0.94 \mathrm{~g}$.

Table 1 summarizes the parameters that characterized the dynamic response of models FS and FSD during the different seismic simulations. In this table, $T$ is the period of vibration, $\xi$ is the damping ratio, $D$ is the maximum drift expressed as percentage of the story height, $v_{\max }$ is the maximum relative displacement, $\ddot{v}_{\max }^{t}$ is the maximum absolute response acceleration, $v_{r}$ is the residual displacement after each test, $V_{E}$ is the total energy $E$ input by the earthquake expressed in terms of an equivalent velocity by $V_{E}=\sqrt{2 E / M}$, and SPL is the Structural Performance Level according to the limiting values of $D$ defined in Table C1-3 of FEMA-356. $T$ and $\xi$ were calculated from the time history of response displacements $v$ measured during free vibration tests conducted after each seismic simulation. More precisely, the damping ratio was obtained considering two response peaks which are $r$ cycles apart, $v_{n}$ and $v_{n+r}$, by $\xi=\ln \left(v_{n} / v_{n+r}\right) /(2 \pi r) ; \ddot{v}_{\max }^{t}$ was obtained experimentally by averaging the accelerations measured by the accelerometers 2 and 3 in the direction of the shaking.

For relating the SPLs with the values of D according to Table C1-3, the test model FS was considered as a steel moment frame, whereas model FSD was treated as a Braced Steel Frame. The discrete SPLs established by FEMA-356 are: Immediate Occupancy level (S1), Damage Control Range (S2), Life Safety (S3), Limited Safety Range (S4), Collapse prevention (S5) and Not Considered (S6). Specimen FS collapsed in the seismic simulation corresponding to $1.1 \mathrm{~g}$, and specimen FSD in the seismic simulation corresponding to $2.23 \mathrm{~g}$. It is worth noting that in specimen FSD, the dampers broke completely (splitting in two parts) before the end of the seismic simulation corresponding to $2.23 \mathrm{~g}$, and from this instant the system behaved as a bare structure (i.e. without hysteretic dampers). The values of $v_{r}$ at the end of each seismic simulation before the one that caused the collapse of the structure were below $0.39 \%$ in specimen FS and below $0.13 \%$ in specimen FSD. These residual displacements at the end of a given seismic simulation are negligible on the structural global response in the following test.

In both test models and for all seismic simulations, the reinforcement steel of the slab remained elastic. The plastic mechanism of both test models was characterized by the formation of plastic hinges at both ends of the columns. In test model FS, the formation of plastic hinges in the columns occurred during the seismic simulation in which PGA $=0.47 \mathrm{~g}$. In test model FSD, the onset of yielding of the dampers occurred in the seismic simulation corresponding to $\mathrm{PGA}=0.31 \mathrm{~g}$, prior to plastification of the columns. The columns started to plastify during the seismic simulation corresponding to $\mathrm{PGA}=0.94 \mathrm{~g}$.

Figures $10 \mathrm{a}, \mathrm{b}$ show, with open circles, discrete pairs of values for the displacement, $v$, and the restoring force, $F_{S}$, recorded at the instants in which the velocity was zero (i.e. $\dot{v}=0$ ). The equation of dynamic equilibrium of the slab is: 
Table 1 Response parameters obtained from the experiments

\begin{tabular}{|c|c|c|c|c|c|c|c|c|c|c|c|c|c|c|c|c|}
\hline \multirow[t]{2}{*}{ PGA (s) } & \multicolumn{8}{|c|}{ Model FS } & \multicolumn{8}{|c|}{ Model FSD } \\
\hline & $T(\mathrm{~s})$ & $\%$ & $D(\%)$ & $V_{\max }(\mathrm{mm})$ & $\ddot{V}_{\max }^{t}(\mathrm{~mm})$ & $v_{r}(\mathrm{~mm})$ & $V_{E}(\mathrm{~cm} / \mathrm{s})$ & SPL & $T(s)$ & $\%$ & $D(\%)$ & $V_{\max }(\mathrm{mm})$ & $\ddot{V}_{\max }^{t}(\mathrm{~mm})$ & $v_{r}(\mathrm{~mm})$ & $V_{E}(\mathrm{~cm} / \mathrm{s})$ & SPL \\
\hline 0.16 & 0.32 & 1.6 & 0.9 & 11.9 & 0.46 & 0 & 38 & S1 & 0.16 & 1.6 & 0.34 & 4.3 & 0.60 & 0 & 30 & S1 \\
\hline 0.31 & 0.32 & 2.1 & 1.7 & 21.8 & 0.79 & 0.3 & 90 & $\mathrm{~S} 2$ & 0.16 & 2.1 & 0.70 & 8.8 & 1.05 & 0.3 & 68 & $\mathrm{~S} 1$ \\
\hline 0.47 & 0.32 & 2.5 & 2.4 & 31.2 & 1.03 & 1.9 & 152 & S3 & 0.16 & 2.5 & 1.04 & 13.1 & 1.3 & 0.8 & 142 & $\mathrm{~S} 2$ \\
\hline 0.62 & 0.32 & 3.1 & 2.7 & 34.6 & 1.06 & 2.6 & 187 & S3 & 0.16 & 3.1 & 1.22 & 15.4 & 1.44 & 0.7 & 181 & $\mathrm{~S} 3$ \\
\hline 0.78 & 0.32 & 3.2 & 2.9 & 37.8 & 1.07 & 3.2 & 222 & $\mathrm{~S} 4$ & 0.17 & 3.2 & 1.42 & 17.9 & 1.55 & 0.6 & 220 & S3 \\
\hline 0.94 & 0.32 & 3.5 & 4.0 & 51.5 & 1.13 & 4.9 & 303 & S5 & 0.17 & 3.5 & 1.84 & 23.3 & 1.78 & 0.23 & 304 & S4 \\
\hline 1.10 & 0.32 & 3.5 & 7.7 & 98.2 & 1.01 & 31.2 & 428 & a & 0.17 & 3.5 & 2.33 & 29.4 & 1.94 & 1.6 & 393 & S5 \\
\hline 2.23 & & & & & & & & & 0.17 & 3.5 & 4.17 & 52.6 & 2.07 & 17 & 445 & a \\
\hline
\end{tabular}

a Collapse 

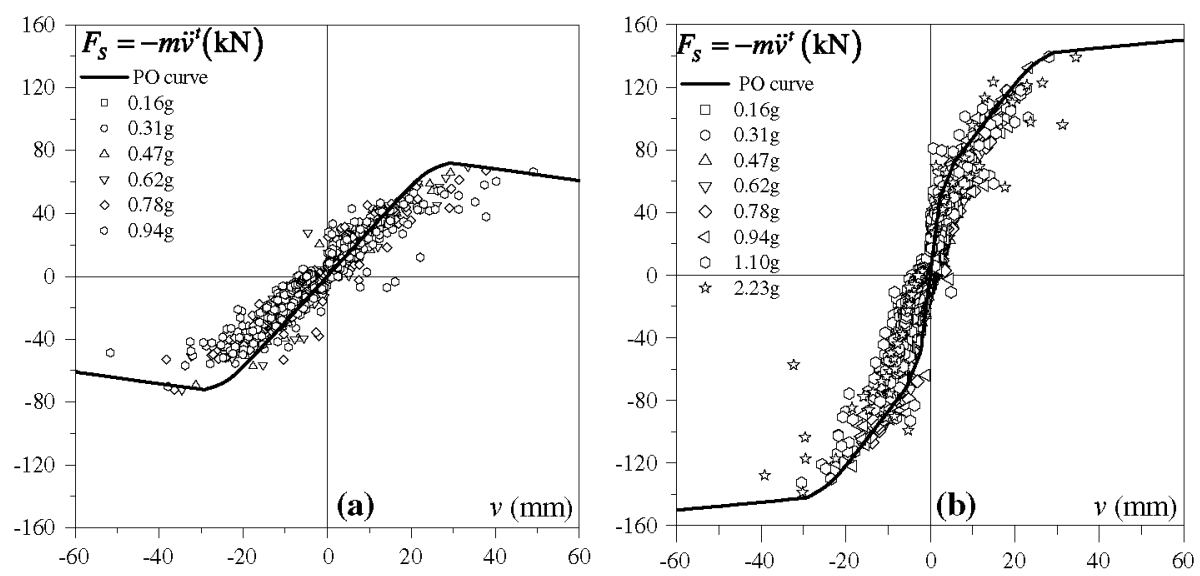

Fig. 10 Pairs of values $\left(v, F_{S}\right)$ obtained from the test at the instants of $\dot{v}=0$ and capacity curve estimated numerically for: a FS model; $\mathbf{b}$ FSD model

Fig. 11 Comparison between experimental and numerical axial load-displacement curves of one of the hysteretic dampers of specimen FSD under the seismic simulation corresponding to $1.1 \mathrm{~g}$

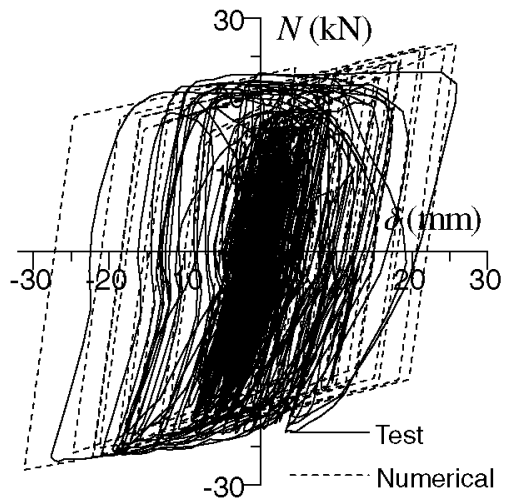

$$
m \ddot{v}^{t}+c \dot{v}+F_{S}=0
$$

where $c$ is the damping coefficient $(c=4 m / T)$. At the instants of $\dot{v}=0$ the damping force $c \dot{v}$ is null, and therefore the inertial force is equilibrated entirely by the restoring force, i.e. $F_{S}=-m \ddot{v}^{t}$. Consequently, $F_{S}$ was computed at the instants when the velocity was zero by multiplying the absolute acceleration $\ddot{v}^{t}$ by the mass of the system $m$.

Figure 11 shows, with thin solid lines, the experimental axial load-displacement curve, $N-\delta$, obtained for one of the dampers of specimen FSD during the seismic simulation corresponding to $1.1 \mathrm{~g}$.

\section{Estimation of capacity curves with numerical models and comparison with test results}

In order to estimate the capacity curves of the FS and FSD models, two non-linear 3D finite element models were developed using Engineer's Studio software (Maekawa et al. 2003). Both models were subjected to a displacement-controlled SPO analysis including second 


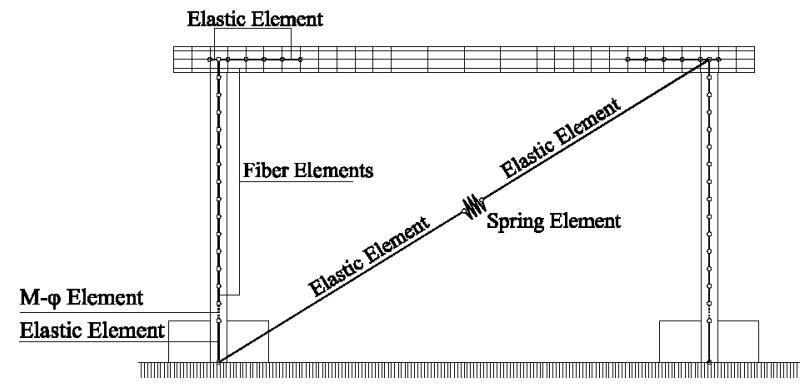

(a)

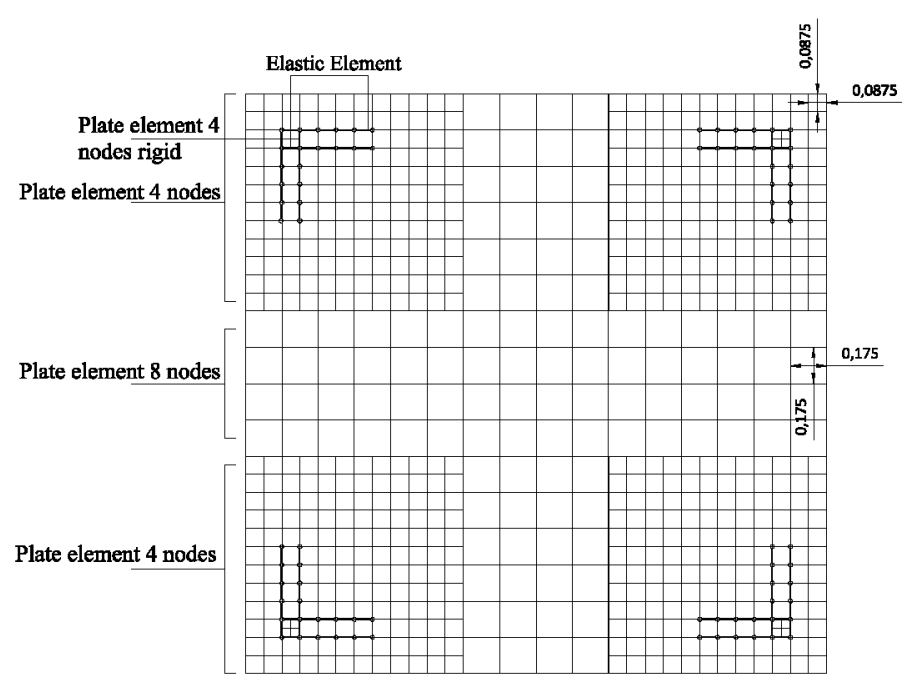

(b)

Fig. 12 Definition of the finite element model: a elevation; $\mathbf{b}$ plan

order (P- $\Delta$ ) effects. Figure 12 shows the finite element mesh of the models. The RC slab was modeled with non-linear rectangular isoparametric plate elements. In the vicinity of the columns, the plate elements had 4 nodes and their size in plan was $87.5 \times 87.5 \mathrm{~mm}^{2}$. For the rest of the slab, plate elements with 8 nodes and $175 \times 175 \mathrm{~mm}^{2}$ were used. Each plate element was internally subdivided into six layers. The top and the bottom layers included the longitudinal reinforcement of the slab. The constitutive relationships of the materials were formulated using the non-linear mechanics of reinforced concrete proposed by Maekawa et al. (2003). The C-shape steel sections that form the shearheads were modeled with elastic frame elements connected to the nodes of the plate element. The columns were modeled with $84 \mathrm{~mm}$-long fiber frame elements. The base of the column was modeled with a momentcurvature, M- $\phi$, element in order to simulate a semi-rigid union. The FSD model was defined attaching two diagonal bars that represented the hysteretic dampers to the FS numerical model. Each diagonal bar consisted of two elastic elements and one non-linear spring connected in series.

The base shear versus top displacement relationship (capacity curve) obtained from the SPO analysis is shown in bold lines in Fig. 10a, b. To better compare the capacity curve 

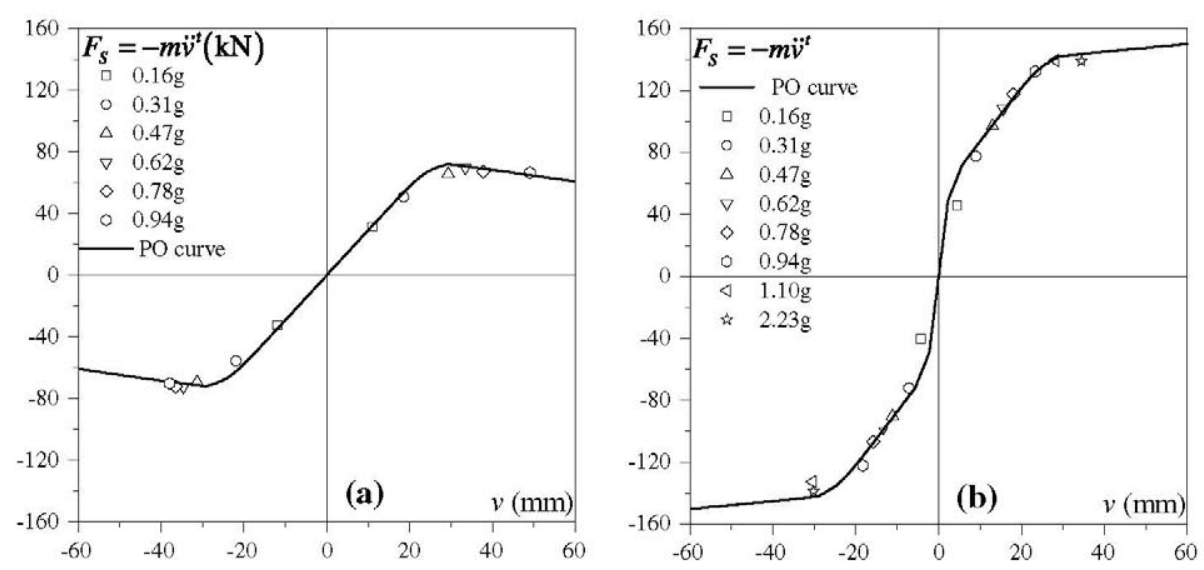

Fig. 13 Pairs of values $\left(v, F_{S}\right)$ obtained from the test at the instants of $\dot{v}=0$ and maximum absolute response acceleration and capacity curve estimated numerically for: a FS model; b FSD model

obtained numerically with the experimental results, the pairs of values $\left(v, F_{S}\right)$ corresponding to the maximum absolute acceleration attained by the slab in each seismic simulation were selected from Fig. 10a, b, and they are drawn in Fig. 13a, b, respectively. It can be seen that there is a good agreement between the test results and the curve obtained with the finite element models.

In order to check the ductility demanded of the hysteretic dampers, non-linear time-history analyses were performed and the numerical outcomes were compared with the experimental results. The dashed lines in Fig. 11 draw the numerical axial load-displacement curve obtained from the non-linear time-history analyses. It can be observed that, qualitatively, both curves fit quite well. If the comparison is made quantitatively, in terms of maximum axial displacement and total amount of dissipated energy, the results are also satisfactory. In the test, the energy dissipated by the damper was $17.56 \mathrm{kNm}$ and the maximum axial displacement $27 \mathrm{~mm}$; the corresponding predicted values with the numerical model were $16.42 \mathrm{kNm}$ and $31 \mathrm{~mm}$, respectively.

\section{Comparison between prediction with NSPs and experimental results for specimen FSD}

In this section, the maximum response of the structure with hysteretic dampers, FSD, is predicted with current NSPs for four levels of ground motion corresponding to the seismic simulations with $\mathrm{PGA}=0.31 \mathrm{~g}, \mathrm{PGA}=0.62 \mathrm{~g}, \mathrm{PGA}=0.94 \mathrm{~g}$ and $\mathrm{PGA}=1.1 \mathrm{~g}$ reported in Sect. 2. Each simulation produced a different level of damage on the structure. Similar to previous studies (Cardone 2007; Causevic and Mitrovic 2010), the prediction with NSPs was calculated using a smoothed spectrum $S_{a}-T$. The smoothed spectrum for each level of PGA was obtained from the elastic response spectrum calculated with the inherent damping measured during the tests, by applying the rule of equal areas (Vidic et al. 1994). Figure 14 shows with simple lines the unsmoothed spectra, and with bold lines their counterpart smoothed ones. It is worth noting in this figure that the comparison of the elastic acceleration responses depends on the natural periods of the two specimens FS and FSD, $T=0.17 \mathrm{~s}$ and $T=0.32 \mathrm{~s}$, respectively, which are indicated with a vertical line. As seen in the figure, within the spectral 
Fig. 14 Elastic response spectra for the FSD test model under three different levels of PGA

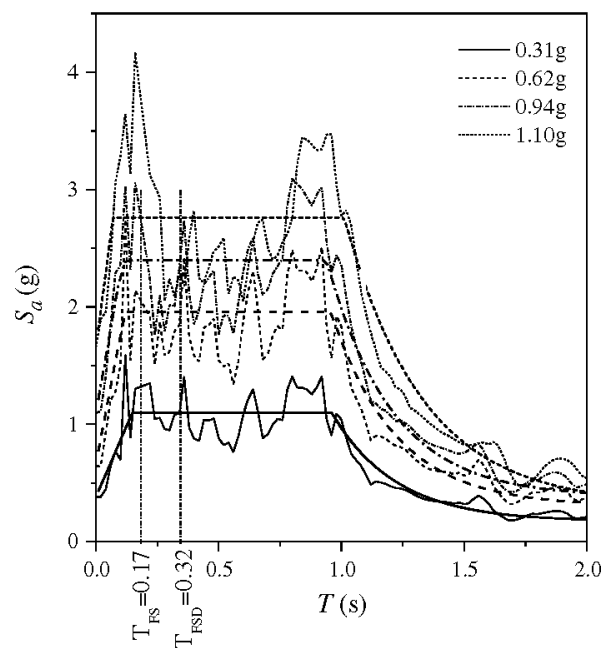

window delimited by about 0.15 and $0.9 \mathrm{~s}$ the spectra are approximately flat, and the periods of both specimens FS and FSD are located within this period range.

\subsection{Capacity spectrum method}

The CSM presented in FEMA 440 is an improved equivalent linearization procedure as a modification to the CSM of ATC-40. The performance point of the structure is obtained in terms of maximum displacement by direct comparison of the capacity and demand curves in an Acceleration Displacement Response Spectra (ADRS) format, in which spectral acceleration, $S_{a}$, is plotted against spectral displacement, $S_{d}$. The performance point is obtained by the intersection of the capacity curve with the demand curve. The latter is obtained from a $5 \%$ damped elastic response spectrum modified by two factors: (1) factor $B\left(\beta_{\text {eff }}\right)$ to adjust the initial response spectrum to the appropriate level of effective damping, $\beta_{\text {eff }}$; and (2) factor $M$ to obtain the modified ADRS demand curve (MADRS). Values of $B$ and $M$ can be obtained with the following expressions:

$$
\begin{aligned}
B & =\frac{4}{5.6-\ln \left(\beta_{e f f}\right)} \\
M & =\left(\frac{T_{e f f}}{T_{0}}\right)^{2} \frac{1+\alpha(\mu-1)}{\mu}
\end{aligned}
$$

The effective linear parameters (effective period $T_{\text {eff }}$ and effective damping $\beta_{\text {eff }}$ ) are functions of the capacity curve, the initial period and damping, and the ductility demand. They can be obtained from the following expressions:

$$
\begin{aligned}
& \beta_{\text {eff }}=A(\mu-1)^{2}-B(\mu-1)^{3}+\beta_{0} \\
& T_{\text {eff }}=\left(G(\mu-1)^{2}-H(\mu-1)^{3}+1\right) T_{0} \quad 1.0 \leq \mu \leq 4.0 \\
& \beta_{\text {eff }}=C+D(\mu-1)+\beta_{0} \quad 4.0 \leq \mu \leq 6.5 \\
& T_{\text {eff }}=(I+J(\mu-1)+1) T_{0} \quad 4.0 \leq
\end{aligned}
$$


Fig. 15 CSM idealized capacity curve and target displacement in ADRS format (specimen FSD)

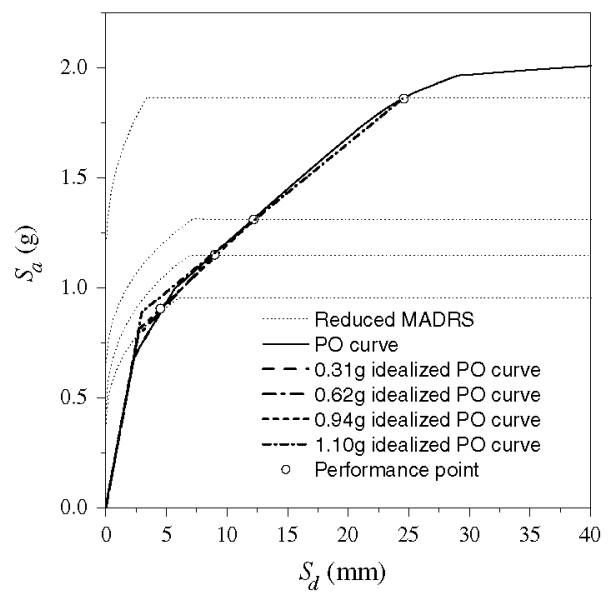

Table 2 CSM results for specimen FSD

\begin{tabular}{|c|c|c|c|c|c|c|c|c|}
\hline & \multicolumn{2}{|c|}{ PGA $0.31 \mathrm{~g}$} & \multicolumn{2}{|c|}{ PGA $0.62 \mathrm{~g}$} & \multicolumn{2}{|c|}{ PGA $0.94 \mathrm{~g}$} & \multicolumn{2}{|c|}{ PGA $1.10 \mathrm{~g}$} \\
\hline & CSM & Test & $\mathrm{CSM}$ & Test & CSM & Test & CSM & Test \\
\hline$T_{e f f}(\mathrm{~s})$ & 0.13 & 0.16 & 0.16 & 0.16 & 0.17 & 0.16 & 0.28 & 0.17 \\
\hline$P P(\mathrm{~mm})$ & 4.5 & 8.7 & 9 & 15.4 & 11 & 23.2 & 24.5 & 29.4 \\
\hline$F_{S, \max }(\mathrm{kN})$ & 64.0 & 79.8 & 83.0 & 108.6 & 91.0 & 132.8 & 134.4 & 139.5 \\
\hline
\end{tabular}

$$
\begin{aligned}
& \beta_{\text {eff }}=E\left[\frac{F(\mu-1)-1}{[F(\mu-1)]^{2}}\right]\left(\frac{T_{e f f}}{T_{0}}\right)^{2}+\beta_{0} \\
& T_{e f f}=\left(K\left(\sqrt{\frac{(\mu-1)}{1+L(\mu-2)}}-1\right)+1\right) T_{0} \quad \mu>6.5
\end{aligned}
$$

Here, $\mu$ is the ductility ratio. $\beta_{0}$ and $T_{0}$ are the initial damping and the initial period of vibration of the structure defined by an idealized bi-linear curve as shown in Fig. 15. In this bilinear curve, the elastic slope is equal to the initial stiffness in the capacity curve, and the post-yield branch should have a slope such that (1) it passes through the performance point, and (2) the areas below the SPO curve and the idealized curve are the same. Coefficients $A$ to $L$ are defined in Tables 6-1 and 6-2 in FEMA-440. Since all these parameters are functions of ductility, which is the objective of the analysis, the solution must be found using an iterative technique.

Table 2 compares the results of the improved CSM prediction in terms of effective period $T_{\text {eff }}$, displacement corresponding to the performance point $P P$, and maximum restoring force $F_{S, \max }$, with the experimental results for the seismic simulations corresponding to $\mathrm{PGA}=0.31 \mathrm{~g}, \mathrm{PGA}=0.62 \mathrm{~g}, \mathrm{PGA}=0.94 \mathrm{~g}$ and $\mathrm{PGA}=1.1 \mathrm{~g}$. In turn, Fig. 15 offers a graphic view of the idealized capacity curve and the target displacement predicted at the last step of the iterative process in ADRS format.

\subsection{Displacement coefficient method}

The improved version of the DCM in FEMA-440 estimates maximum global displacement (target displacement) of the structure at roof level, $\delta_{t}$, by multiplying the elastic response of an equivalent SDOF system by a series of coefficients- $C_{0}$ to $C_{2}$-as indicated in Eq. (7): 
Table 3 DCM results for specimen FSD

\begin{tabular}{|c|c|c|c|c|c|c|c|c|}
\hline & \multicolumn{2}{|c|}{ PGA $0.31 \mathrm{~g}$} & \multicolumn{2}{|c|}{ PGA $0.62 \mathrm{~g}$} & \multicolumn{2}{|c|}{ PGA $0.94 \mathrm{~g}$} & \multicolumn{2}{|c|}{ PGA $1.10 \mathrm{~g}$} \\
\hline & DCM & Test & DCM & Test & DCM & Test & DCM & Test \\
\hline$T_{e}(\mathrm{~s})$ & 0.11 & 0.16 & 0.11 & 0.16 & 0.11 & 0.17 & 0.11 & 0.17 \\
\hline$S_{a}\left(\mathrm{~m} / \mathrm{s}^{2}\right)$ & 10.1 & - & 19.2 & - & 23.6 & - & 27.0 & - \\
\hline$\delta_{t}(\mathrm{~mm})$ & 5.6 & 8.7 & 17.6 & 15.4 & 25.0 & 23.3 & 29.5 & 29.4 \\
\hline$F_{S, \max }(\mathrm{kN})$ & 71.3 & 79.8 & 113.7 & 108.6 & 135.5 & 132.8 & 142.3 & 139.5 \\
\hline
\end{tabular}

$$
\delta_{t}=C_{0} \cdot C_{1} \cdot C_{2} \cdot S_{a} \cdot \frac{T_{e}^{2}}{4 \cdot \pi^{2}} \cdot g
$$

Here, $S_{a}$ is the maximum response acceleration of the equivalent SDOF system obtained from an elastic response spectrum assuming a $5 \%$ damping ratio. $T_{e}$ is the effective fundamental period of the equivalent SDOF given by $T_{e}=T_{i} \cdot \sqrt{K_{i} / K_{e}}$ where $T_{i}$ is the elastic fundamental period and $K_{i}$ is the lateral stiffness of the structure. To determine the dynamic properties of the equivalent SDOF, an iterative graphic method should be applied so that the areas under the capacity and idealized curves are equal. Accordingly, the effective lateral stiffness $K_{e}$, is taken as the secant stiffness corresponding to a base shear force equal to $60 \%$ of the effective yield strength of the structure, $V_{y}$. In Eq. (7), $C_{0}$ relates the spectral displacement of the equivalent SDOF system with the roof displacement of the building multi-degree-of-freedom (MDOF) system. $C_{1}$ relates the expected maximum inelastic displacements with respect to those calculated for linear elastic response, as follows:

$$
C_{1}=1+\frac{R-1}{a T_{e}^{2}}
$$

where the constant $a$ is equal to 130,90 and 60 for site classes B, C and D, respectively, and $R$ is the ratio of required elastic strength to the yield strength defined by means of Eq. (9):

$$
R=\frac{S_{a} \cdot W}{V_{y}} \cdot C_{m}
$$

where $W$ is the effective seismic weight and $C_{m}$ is the effective mass factor. The coefficient $C_{2}$ need only to be applied to structures that exhibit significant stiffness and/or strength degradation, and it can be obtained as follows:

$$
C_{2}=1+\frac{1}{800}\left(\frac{R-1}{T}\right)^{2}
$$

Again, an iterative process is necessary if the estimated target displacement and the predicted performance point are much different.

Below, Table 3 summarizes the results of the equivalent period, $T_{e}$, target displacement, $\delta_{t}$, and the maximum restoring force, $F_{S, \max }$, predicted with the improved DCM from FEMA440 , and compares them with the experimental results corresponding to the seismic simulations with $\mathrm{PGA}=0.31 \mathrm{~g}, \mathrm{PGA}=0.62 \mathrm{~g}, \mathrm{PGA}=0.94 \mathrm{~g}$ and $\mathrm{PGA}=1.1 \mathrm{~g}$. Figure 16 offers a graphic view of the idealized capacity curve and the target displacement predicted in the last step of the iterative process. 
Fig. 16 DCM idealized capacity curve and target displacement (specimen FSD)
Fig. 17 N2 method idealized capacity curve and target displacement (specimen FSD)
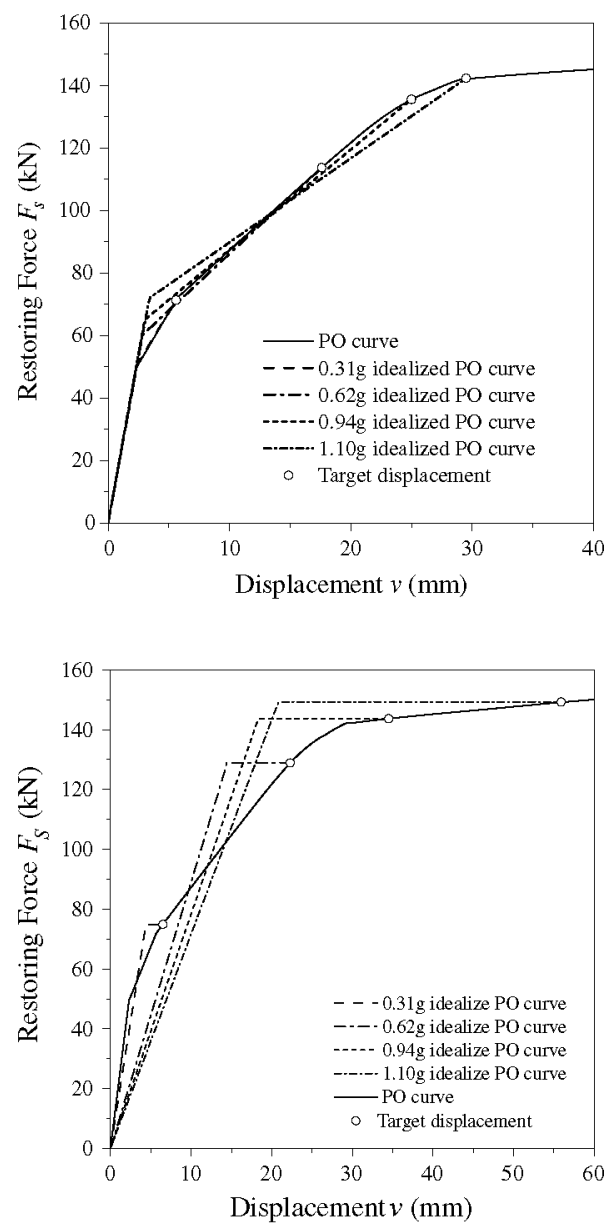

\section{$4.3 \mathrm{~N} 2$ method}

This method is called N2 because it is non-linear and it uses two mathematical models: the response spectrum method and non-linear SPO analysis (Fajfar and Gaspersic 1996). It is based on the inelastic demand spectra of an SDOF system (Vidic et al. 1994) following the equal displacement rule for systems with medium and long periods.

The $\mathrm{N} 2$ method assumes that the target displacement $d_{t}$ of the structure at the control node can be obtained from the elastic displacement $d_{e t}^{*}$ of an equivalent SDOF system. The equivalent SDOF system is defined by an elastic-perfectly plastic bilinear idealization of the SPO curve, imposing that (1) the yield strength $F_{y}^{*}$ is equal to the strength of the target point, and (2) the yield displacement $d_{y}^{*}$ is selected so that the areas below both curves are equal, as shown in Fig. 17. The elastic equivalent period $T^{*}$ of the idealized bilinear system can be determined as

$$
T^{*}=2 \pi \sqrt{\frac{m^{*} d_{y}^{*}}{F_{y}^{*}}}
$$


Table 4 N2 method results for specimen FSD

\begin{tabular}{|c|c|c|c|c|c|c|c|c|}
\hline & \multicolumn{2}{|c|}{ PGA $0.31 \mathrm{~g}$} & \multicolumn{2}{|c|}{ PGA $0.62 \mathrm{~g}$} & \multicolumn{2}{|c|}{ PGA $0.94 \mathrm{~g}$} & \multicolumn{2}{|c|}{ PGA $1.10 \mathrm{~g}$} \\
\hline & $\mathrm{N} 2$ & Test & $\mathrm{N} 2$ & Test & N2 & Test & $\mathrm{N} 2$ & Test \\
\hline$T_{e}(\mathrm{~s})$ & 0.13 & 0.16 & 0.18 & 0.16 & 0.19 & 0.17 & 0.19 & 0.17 \\
\hline$S_{a}\left(\mathrm{~m} / \mathrm{s}^{2}\right)$ & 10.8 & - & 19.3 & - & 23.0 & - & 27.0 & - \\
\hline$\delta_{t}(\mathrm{~mm})$ & 6.4 & 8.7 & 22.3 & 15.45 & 34.5 & 23.3 & 55.9 & 29.4 \\
\hline$F_{S, \max }(\mathrm{kN})$ & 74.5 & 79.8 & 128.8 & 108.6 & 143.9 & 132.8 & 149.2 & 139.5 \\
\hline
\end{tabular}

where $m^{*}$ is the equivalent mass of the SDOF system. The elastic displacement $d_{e t}^{*}$ of the equivalent SDOF is obtained from the spectral acceleration at the period $T^{*}, S_{a}\left(T^{*}\right)$ by Eq. (12):

$$
d_{e t}^{*}=S_{a}\left(T^{*}\right)\left(\frac{T^{*}}{2 \pi}\right)^{2}
$$

The inelastic displacement $d_{t}^{*}$ of the equivalent SDOF system can be derived from the elastic displacement $d_{e t}^{*}$, applying a simplified version of the equations proposed by Vidic et al. (1994) and adopted in Eurocode 8, as follows:

$$
\begin{aligned}
& d_{t}^{*}=\frac{1}{R_{\mu}}\left[1+\left(R_{\mu}-1\right) \frac{T_{c}}{T^{*}}\right] d_{e t}^{*} \text { for } T^{*}<T_{c} \\
& d_{t}^{*}=d_{e t}^{*} \text { for } T^{*} T_{c}
\end{aligned}
$$

where $T_{c}$ is the corner period where the spectrum changes from the constant acceleration segment to the constant velocity segment, and $R_{\mu}$ can be determined as the ratio between the accelerations corresponding to the elastic and inelastic systems.

$$
R_{\mu}=\frac{S_{a}\left(T^{*}\right) m^{*}}{F_{y}^{*}}
$$

As the properties of the equivalent SDOF system depend on the $d_{t}^{*}$ selected, an iterative procedure is also required if the $d_{t}^{*}$ obtained differs greatly from the value estimated for the determination of the idealized elastic-perfectly plastic capacity curve.

Table 4 summarizes the predictions of the $\mathrm{N} 2$ method, and compares them with the experimental results obtained for the test with $\mathrm{PGA}=0.31,0.62,0.94$ and $1.1 \mathrm{~g}$. A view of the idealized capacity curve and target displacement predicted in the last step of the iterative process can be seen in Fig. 17.

\subsection{Comparison of three NSPs}

Figure 18 shows the error coefficient $C_{d}$ (=prediction/test) of each NSP in predicting the maximum displacement (Fig. 18a), and the maximum base shear (Fig. 18b). Under the low intensity earthquake corresponding to $\mathrm{PGA}=0.31 \mathrm{~g}$, the structure with FSD dampers behaved at an "immediate occupancy" structural performance level. For this performance level, the prediction given by all NSPs underestimated the maximum displacement and the maximum base shear. $C_{d}$ ranged from 0.51 (for CSM) to 0.73 (for N2) in the case of the maximum displacement, and from 0.80 (for CSM) to 0.93 (for N2) for the maximum base shear. The method N2 provided the best approximation and the CSM method the worst. 


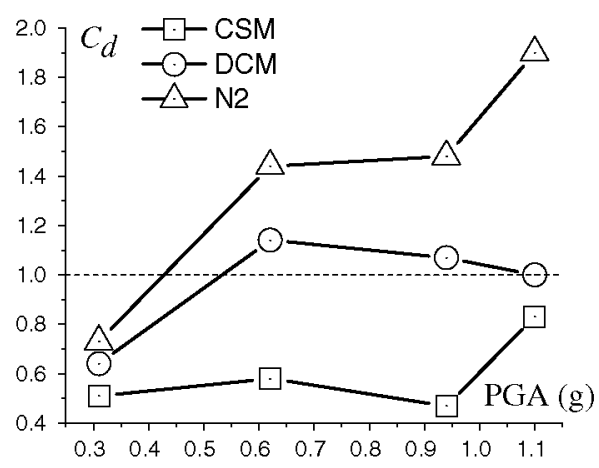

(a) Values of $C_{d}$ for maximum displacement

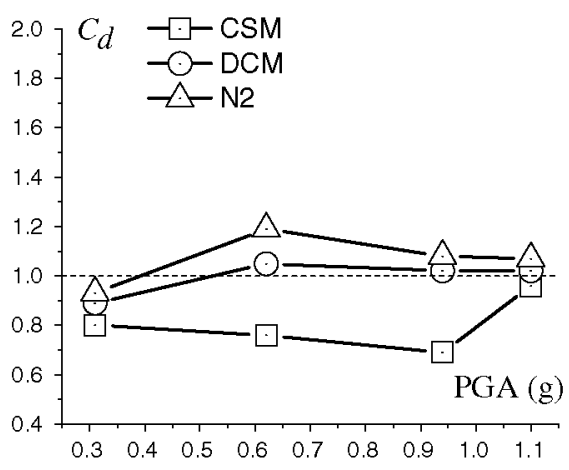

(b) Values of $C_{d}$ for maximum base shear

Fig. 18 Error coefficients $C_{d}$ of NSPs for a maximum displacement and $\mathbf{b}$ maximum base shear

For the medium intensity earthquake corresponding to $\mathrm{PGA}=0.62 \mathrm{~g}$, the structural performance level observed was "life safety". For this performance level, the prediction given by the CSM clearly underestimated the maximum displacement $\left(C_{d}=0.58\right)$ and the maximum base shear $\left(C_{d}=0.76\right)$. The prediction of the DCM was very close to the test results ( $C_{d}=1.14$ for the maximum displacement and $C_{d}=1.05$ for the maximum shear force), while that provided by the $\mathrm{N} 2$ method overestimated the response in terms of maximum displacement $\left(C_{d}=1.44\right)$ and was close to the test results $\left(C_{d}=1.19\right)$ for the maximum shear force.

Under the high intensity earthquake corresponding to $\mathrm{PGA}=0.94 \mathrm{~g}$, the structure exhibited a "limited safety range" performance level. Similarly to the "life safety" level, in this case the CSM underestimated both the maximum displacement $\left(C_{d}=0.47\right)$ and the maximum base shear $\left(C_{d}=0.69\right)$, while the DCM predicted both parameters of the experimental response $\left(C_{d}=1.07\right.$ for the maximum displacement and $C_{d}=1.02$ for the maximum base shear). The N2 method overestimated the response for the maximum displacement $\left(C_{d}=1.48\right)$, but provided a good approximation for the maximum base shear $\left(C_{d}=1.08\right)$.

In the prediction of maximum displacement, the mean value of the error coefficient $E\left(C_{d}\right)$ taking into account the three levels of performance was 0.52 for CSM, 0.95 for $\mathrm{DCM}$ and 1.22 for the $\mathrm{N} 2$ method. The corresponding coefficients of variation $\operatorname{COV}\left(C_{d}\right)=\left(C_{d}\right) / E\left(C_{d}\right)$ (here $\sigma$ is the standard deviation), were $0.09,0.23$ and 0.28 , respectively. The prediction of the maximum base shear, $E\left(C_{d}\right)$, gave 0.75 for CSM, 0.99 for DCM and 1.07 for $\mathrm{N} 2$, and the corresponding standard deviations were $0.06,0.07$ and 0.10 .

\section{Comparison between prediction with NSPs and experimental results for specimen FS}

For the sake of thoroughness, an attempt was made to predict the experimental response of the structure without dampers, FS, with the NSPs. In contrast to specimen FSD, the specimen FS exhibited an early degradation of strength characterized by a negative postelastic stiffness in the pushover curve that started immediately after the yield strength was reached. This strength degradation affects the applicability of the CSM, DCM and N2 method. In the presence of strength degradation, FEMA-440 recommends limiting the maximum value of the design force reduction factor $R$ to a value $R_{\max }$. For specimen FS, the formula 
Table 5 CSM results for specimen FS

Table 6 DCM results for specimen FS

\begin{tabular}{lccccc}
\hline & \multicolumn{2}{l}{ PGA 0.31g } & & \multicolumn{2}{l}{ PGA 0.62g } \\
\cline { 2 - 3 } & CSM & Test & & CSM & Test \\
\hline$T_{\text {eff }}(\mathrm{s})$ & 0.32 & 0.32 & & 0.39 & 0.32 \\
$P P(\mathrm{~mm})$ & 27.96 & 21.8 & & 47 & 34.6 \\
$F_{S, \max }(\mathrm{kN})$ & 71.16 & 33.2 & & 72 & 72 \\
\hline
\end{tabular}

\begin{tabular}{lccccc}
\hline & \multicolumn{2}{c}{ PGA 0.31g } & & \multicolumn{2}{c}{ PGA 0.62g } \\
\cline { 2 - 3 } & DCM & Test & & DCM & Test \\
\hline$T_{e}(\mathrm{~s})$ & 0.31 & 0.32 & & 0.32 & 0.32 \\
$S_{a}\left(\mathrm{~m} / \mathrm{s}^{2}\right)$ & 10.8 & - & & 19.2 & - \\
$\delta_{t}(\mathrm{~mm})$ & 28.7 & 21.8 & & 59.2 & 34.6 \\
$F_{S, \text { max }}(\mathrm{kN})$ & 72 & 33.2 & & 72 & 72 \\
\hline
\end{tabular}

of FEMA-440 leads to $R_{\max }=2.75$, which limits the applicability of the DCM and CSM to only the seismic simulations corresponding to PGA $=0.31$ and $0.62 \mathrm{~g}$. As for the $\mathrm{N} 2$ method, it cannot be applied to specimen FS because the idealization of the SPO curve with an elastic-perfectly plastic model, applying the rule of equal areas, would lead to the meaningless behavior that the elastic equivalent period decreases as the system undergoes plastic deformations. Tables 5 and 6 summarize the prediction of DCM and CSM, comparing them with the experimental results obtained for the test with $\mathrm{PGA}=0.31$ and $0.62 \mathrm{~g}$,

\section{Conclusions}

In this study, the response in terms of maximum displacement and maximum base shear of a structure equipped with hysteretic dampers was obtained experimentally through shaking table tests. The response was obtained for three levels of structural performance ("immediate occupancy", "life safety" and "limited safety range") associated with earthquakes having peak ground accelerations (PGA) of $0.31,0.62$ and $0.94 \mathrm{~g}$, respectively. The response was compared with the prediction provided by three different Non-linear Static Procedures (NSPs): the improved versions of the Capacity Spectrum Method (CSM) and of the Displacement Coefficient Method (DCM) from FEMA-440, and the N2 Method from Eurocode 8.

It was found that for the three levels of structural performance, the CSM provided the worst (underestimated) prediction, with errors ranging from 0.47 to 0.58 for the maximum displacement, and from 0.69 to 0.80 for the maximum base shear. In contrast, the DCM method predicted values close to the experimental results, especially for PGA $=0.62 \mathrm{~g}$ and $\mathrm{PGA}=0.94 \mathrm{~g}$, with errors ranging from 0.64 to 1.14 for the maximum displacement, and from 0.89 to 1.05 for the maximum base shear. The N2 method also provided reasonably good results, and proved better in predicting the maximum base shear (errors ranging from 0.93 to 1.19) than in the prediction of maximum displacement (errors ranging from 0.73 to 1.48).

Any one of the methods investigated (CSM, DCM and N2) can reproduce with satisfactory accuracy the whole range of responses obtained experimentally for the different seismic simulations. Different adjustments of the parameters involved in each method would have 
led to other conclusions; in this study the parameters were adjusted as determined by each method, according to the corresponding standards and codes. Finally, it is worth noting that there are further limitations that must be taken into account when using these methods, such as the cumulative damage effects.

Acknowledgments This research was funded by the local government of Spain Junta de Andalucía, Consejería de Innovación, Ciencia y Tecnología, Grant number P07-TEP-02610, and Fonds Européen de Dévelopment Regional (FEDER).

\section{Appendix}

The equation of motion of an inelastic SDOF system subjected to a unidirectional horizontal component of an earthquake characterized by the ground acceleration $\ddot{v}_{g}(t)$ is:

$$
M \ddot{v}+C \dot{v}+Q(v)=-M \ddot{v}_{g}
$$

where $M$ is the mass, $C$ is the damping coefficient, $Q(v)$ is the restoring force, $v$ is the relative displacement, $\dot{v}$ and $\ddot{v}$ its first and second derivates with respect to time $t$. Multiplying (A.1) by $d v=\dot{v} d t$ and integrating over the entire duration of the earthquake, i.e. from $t=0$ to $t=t_{o}$, the energy balance equation becomes:

$$
W_{k}+W_{\xi}+W_{s}=E
$$

Here $W_{k}=\int_{0}^{t_{o}} \dot{v} M \ddot{v} d t$ is the kinetic energy, $W_{\xi}=\int_{0}^{t_{o}} C \dot{v}^{2} d t$ is the damping energy, and $W_{s}=\int_{0}^{t_{o}} Q(v) \dot{v} d t$ is the absorbed energy, which comprises the recoverable elastic strain energy, $W_{s e}$, and the irrecoverable plastic energy, $W_{p}$, i.e. $W_{s}=W_{s e}+W_{p}$. The right-handside term, $E=\int_{0}^{t_{o}}-M \ddot{v}_{g} \dot{v} d t$ is, by definition, the seismic input energy. Since $W_{k}+W_{s e}$ is the elastic vibrational energy, $W_{e}$, the Eq.(A.2) can be rewritten as:

$$
W_{e}+W_{p}=E-W_{\xi}
$$

$E-W_{\xi}$ can be expressed in the form of an equivalent velocity $V_{D}$ defined by $V_{D}=$ $\sqrt{2\left(E-W_{\xi}\right) / M}$, so that:

$$
W_{e}+W_{p}=\frac{M V_{D}^{2}}{2}
$$

The SDOF system is assumed to be composed of two elements (springs) connected in parallel. One element is an elastic spring that represents the main structure (i.e. without dampers) and it is characterized by its lateral stiffness $f k$. The vibration period ${ }_{f} T$ of the main structure is ${ }_{f} T=2 \pi \sqrt{M / f_{f} k}$. The other element is a non-linear spring with elastic-perfectly plastic restoring force characteristics, with yield strength ${ }_{s} Q_{y}$, lateral stiffness ${ }_{s} k$ and yield displacement ${ }_{s} v_{y}\left(=_{s} Q_{y} / s k\right)$. The maximum lateral displacement of the SDOF system under the design earthquake characterized by $V_{D}$ is referred to as $v_{\max }$ hereafter. The maximum lateral force sustained by the elastic spring $f Q_{\max }$ is obviously $Q_{\max }={ }_{f} k v_{\max }$. For the sake of convenience, $W_{p}, v_{\max },{ }_{f} Q_{\max }$ and ${ }_{s} Q_{y}$ will be expressed in terms of the non-dimensional parameters, $\eta, \mu,{ }_{f} \alpha_{\max }$ and ${ }_{s} \alpha$ that are defined as follows:

$$
\eta=\frac{W_{p}}{{ }_{s} Q_{y s} v_{y}} ; \mu=\frac{\left(v_{\max }-{ }_{s} v_{y}\right)}{{ }_{s} v_{y}} ;{ }_{f} \alpha_{\max }=\frac{{ }_{f} Q_{\max }}{M g} ;{ }_{s} \alpha=\frac{{ }_{s} Q_{y}}{M g}
$$


Where $g$ is the acceleration of gravity. In addition, two new parameters $K$ and $\alpha_{e}$ are defined as follows:

$$
K=\frac{{ }_{s} k}{{ }_{f} k} ; \alpha_{e}=\frac{2 \pi V_{D}}{g_{f} T}
$$

The elastic vibrational energy $W_{e}$ can be approximated as follows (Benavent-Climent 2011):

$$
W_{e}=\frac{f Q_{\max } v_{\max }}{2}=\frac{f \alpha_{\max }^{2} M^{2} g^{2}}{{ }{ }_{f}}=\frac{M g^{2} T^{2}}{4 \pi^{2}} \frac{f \alpha_{\max }^{2}}{2}
$$

From Eq. (A.5), taking into account Eq. (A.6) and recalling that ${ }_{f} T=2 \pi \sqrt{M /{ }_{f} k}, W_{p}$ can be expressed as:

$$
W_{p}=\eta_{s} Q_{y s} v_{y}=\eta \frac{{ }_{s} Q_{y}^{2}}{{ }_{s} k}=\eta_{s} \alpha^{2} \frac{M^{2} g^{2}}{{ }_{s} k}=\eta_{s} \alpha^{2} \frac{M g^{2}{ }_{f} T^{2}}{4 \pi^{2} K}
$$

Substituting Eqs. (A.7) and (A.8) in Eq. (A.4) and using the parameter $\alpha_{e}$ defined in (A.6) leads to the following expression of the energy balance of the SDOF system:

$$
\frac{f \alpha_{\max }^{2}}{2}+\frac{1}{K} \eta_{s} \alpha^{2}=\frac{\alpha_{e}^{2}}{2}
$$

Using the parameters defined in Eq. (A.5), $f \alpha_{\max }$ can be also expressed as follows:

$$
\begin{aligned}
f_{f} \alpha_{\max } & =\frac{f Q_{\max }}{M g}=\frac{v_{\max f} k}{M g}=\frac{{ }_{s} v_{y}(1+\mu)_{f} k}{M g}=\frac{{ }_{s} Q_{y}(1+\mu)_{f} k}{{ }_{s} k M g}=\frac{{ }_{s} Q_{y}(1+\mu)}{K M g} \\
& =\frac{{ }_{s} \alpha(1+\mu)}{K}
\end{aligned}
$$

Substituting Eq. (A.10) in (A.9) gives:

$$
\frac{f \alpha_{\max }^{2}}{2}+\frac{1}{K} \eta_{s} \alpha^{2}=\frac{\alpha_{e}^{2}}{2}
$$

Based on the results of regression analyses performed with 128 near-fault and 122 far-field earthquake records, Manfredi et al. (2003) proposed a formula that allows one to estimate the ratio $n_{e q}=\eta / \mu$ as follows:

$$
n_{e q}=\frac{\eta}{\mu}=1+c_{1} I_{d} \sqrt{\frac{T_{N H}}{{ }_{f} T}}\left(\frac{K \alpha_{e}}{(K+1)_{s} \alpha}-1\right)^{c_{2}}
$$

Here $T_{N H}$ is the initial period of medium period region in the Newmark and Hall spectral representation of the design earthquake; $I_{d}$ is a seismological parameter (Cosenza and Manfredi 1997) defined by

$$
I_{d}=\frac{\int_{0}^{t_{o}} \ddot{v}_{g}^{2} d t}{P G A \cdot P G V}
$$

Where $P G A$ and $P G V$ are the peak ground acceleration and velocity, respectively. In Eq. (A.12), Manfredi et al. (2003) proposed taking $c_{1}=0.23, c_{2}=0.4$ for near-fault earthquakes; and $c_{1}=0.18, c_{2}=0.6$ for far-field earthquakes. Making $\eta=n_{e q} \mu$ in Eq. (A.11) and solving for $\mu$ gives: 


$$
\mu=K\left\{\sqrt{n_{e q}^{2}+\frac{2 n_{e q}}{K}+\frac{\alpha_{e}^{2}}{{ }_{s} \alpha^{2}}}-n_{e q}\right\}-1
$$

Using Eqs. (A.5) and (A.6), $v_{\max }$ can be expressed as follows:

$$
v_{\max }={ }_{s} v_{y}(1+\mu)=\frac{{ }_{s} Q_{y}}{{ }_{s} k}(1+\mu)=\frac{{ }_{s} \alpha M g}{{ }_{s} k}(1+\mu)=\frac{{ }_{s} \alpha M g}{{ }_{f} k K}(1+\mu)
$$

Finally, substituting Eq. (A.14) in (A.15) gives the following equation that relates the maximum lateral displacement $v_{\max }$ with the stiffness ratio $K$ and the lateral strength of the dampers characterized by ${ }_{s} \alpha$ :

$$
v_{\max }=\frac{{ }_{s} \alpha M g}{{ }_{f} k}\left\{\sqrt{n_{e q}^{2}+\frac{2 n_{e q}}{K}+\frac{\alpha_{e}^{2}}{{ }_{s} \alpha^{2}}}-n_{e q}\right\}
$$

\section{References}

Applied Technology Council, A (1996) ATC-40. Seismic evaluation and retrofit of concrete buildings, Redwood City

Benavent-Climent A (2011) An energy-based method for seismic retrofit of existing frames using hysteretic dampers. Soil Dyn Earthq Eng 31:1385-1396

Benavent-Climent A, Pujades LG, Lopez-Almansa F (2002) Design energy input spectra for moderateseismicity regions. Earthq Eng Struct Dyn 31:1151-1172

Benavent-Climent A, Morillas L, Vico JM (2011) A study on using wide-flange section web under out-of-plane flexure for passive energy dissipation. Earthq Eng Struct Dyn 40:473-490. doi:10.1002/eqe.1031

BSL (2009) The building standard law of Japan, Tokyo: the building center of Japan. English version on CD available at http://118.82.115.195/en/services/publication.html

Bosco M, Ghersi A, Marino EM (2009) On the evaluation of seismic response of structures by nonlinear static methods. Earthq Eng Struct Dyn 38(13):1465-1482. doi:10.1002/eqe.911

Cardone D (2007) Nonlinear static methods vs. experimental shaking table test results. J Earthq Eng 11(6): 847-875. Available from: ISI:000251628100002

Causevic M, Mitrovic S (2010) Comparison between non-linear dynamic and static seismic analysis of structures according to European and US provisions. Bull Earthq Eng 1-23. doi:10.1007/s10518-010-9199-1

Cosenza E, Manfredi G (1997) The improvement of the seismic-resistant design for existing and new structures using damage criteria. In: Fajfar P, Krawinkler H (eds) Seismic design methodologies for the next generation of codes. Balkema, Rotterdam pp 119-130

European Committee for Standarization C (2002) Eurocode 8-design provisions for earthquake resistance of structures, Brussels

Fajfar P (2000) A nonlinear analysis method for performance based design. Eartq Spectr 16(3):573-592

Fajfar P, Gaspersic P (1996) The N2 method for the seismic damage analysis of RC buildings. Earthq Eng Struct Dyn 25(1):31-46. Available from: ISI:A1996TN69700003

Federal Emergency Management Agency (FEMA) (1997) NHERP guidelines for the seismic rehabilitation of buildings. FEMA-273: Provisions. FEMA-274: Commentary. Federal Emergency Management Agency, Washington

Federal Emergency Management Agency (FEMA) (2000) FEMA-356. Prestandard and Commentary for Seismic Rehabilitation of Buildings. Federal Emergency Management Agency, Washington

Federal Emergency Management Agency (FEMA) (2005) FEMA 440, Improvement of Nonlinear Static Seismic Analysis Procedures. Washington

Fragiacomo M, Amadio C, Rajgelj S (2006) Evaluation of the structural response under seismic actions using non-linear static methods. Earthq Eng Struct Dyn 35(12):1511-1531

Freeman S (1988) The capacity spectrum method as a tool for seismic design, In: Proceedings of the 11th European conference on earthquake engineering, Paris

Krawinkler H, Seneviratna GDPK (1998) Pros and cons of a pushover analysis of seismic performance evaluation. Eng Struct 20(4-6):452-464 
Lin YY, Chang KC, Wang YL (2004) Comparison of displacement coefficient method and capacity spectrum method with experimental results of RC columns. Earthq Eng Struct Dyn 33(1):35-48. Available from: ISI:000187863700003

Maekawa K, Pimanmas A, Okamura H (2003) Nonlinear mechanics of reinforced concrete. Taylor \& Francis, London

Manfredi G, Polese M, Cosenza E (2003) Cumulative demand of the earthquake ground motions in the near source. Earthq Eng Struct Dyn 32:1853-1865

Simon K, D'Amore E (1999) Push-over analysis procedure in earthquake engineering. Earthq Spectr 15(3): 417-434

Soong TT, Dargush GF (1997) Passive energy dissipation systems in structural engineering. Wiley, New York

Vidic T, Fajfar P, Fischinger M (1994) Consistent inelastic design spectra: Strength and displacement. Earthq Eng Struct Dyn 23:502-521 